\title{
Tolumonas osonensis sp. nov., isolated from anoxic freshwater sediment, and emended description of the genus Tolumonas
}

Correspondence

Ralph S. Tanner

rtanner@ou.edu

\author{
Matthew E. Caldwell, Toby D. Allen, Paul A. Lawson and Ralph S. Tanner \\ Department of Botany and Microbiology, University of Oklahoma, Norman, OK 73019, USA
}

Within the Gammaproteobacteria, the family Aeromonadaceae comprises five genera: Aeromonas, Oceanimonas, Oceanisphaera, Tolumonas and Zobellella (Lin \& Shieh, 2006; MartinCarnahan \& Joseph, 2005a; Romanenko et al., 2003). However, inclusion of the genus Tolumonas (represented solely by Tolumonas auensis) in this family has been questioned due to the fact that it is oxidase-negative and has a DNA G + C content of $49 \mathrm{~mol} \%$ (Martin-Carnahan \& Joseph, 2005a). T. auensis is also distinctive in its ability to transform substituted aromatic compounds (e.g. phenylacetate, phenylalanine, phenyllactate or phenylpyruvate) into toluene in the presence of a usable carbon source (FischerRomero et al., 1996). T. auensis will also transform tyrosine into phenol in the presence of a primary substrate. While the microbial production of phenol from tyrosine has been known for decades (Berthelot, 1917; Chen \& Levin, 1975; Elsden et al., 1976), to our knowledge, T. auensis is the only bacterium to co-metabolize aromatic compounds into toluene. In this study, isolation of a Gram-negative,

Abbreviation: FAME, fatty acid methyl ester.

The GenBank/EMBL/DDBJ accession number for the 16S rRNA gene sequence of strain OCF $7^{\top}$ is GU370947.

Two supplementary tables are available with the online version of this paper. non-motile, facultatively anaerobic bacterium cultivated from anoxic freshwater sediment is described. Based on data from a polyphasic study incorporating both phylogenetic and phenotypic methods, it is proposed that the unknown bacterium represents a novel species of Tolumonas.

Anoxic freshwater sediment from Oso Creek, Corpus Christi, Texas, USA $\left(27^{\circ} 43^{\prime} \mathrm{N} 97^{\circ} 32^{\prime} \mathrm{W}\right)$ was collected and incubated at $37{ }^{\circ} \mathrm{C}$ in anaerobic enrichment medium (pH 7.3) containing $\left(1^{-1}\right): 10 \mathrm{ml}$ mineral solution (Tanner, 2007), $10 \mathrm{ml}$ vitamin solution (Tanner, 2007), $10 \mathrm{ml}$ trace metal solution (Tanner, 2007), 10 g TES (Sigma-Aldrich), $0.05 \mathrm{~g}$ yeast extract (Difco) and $5.0 \mathrm{~g} \mathrm{NaHCO}_{3}$. The medium was reduced with cysteine sulfide (Tanner, 2007), fructose $(0.5 \%)$ was added as substrate and the gas phase was $\mathrm{N}_{2}: \mathrm{CO}_{2}(80: 20)$. Dilution of the resulting bacterial enrichment and isolation using agar roll tubes (Hungate, 1969) were performed and the isolate was propagated on the same medium except that yeast extract concentration was increased to $0.5 \mathrm{~g} \mathrm{l}^{-1}$. The unknown organism recovered from anoxic freshwater sediment was a Gram-negative, nonmotile rod that appeared singly, in pairs or occasionally in short chains. Growth was observed between 15 and $37^{\circ} \mathrm{C}$, with the optimum growth temperature being $22^{\circ} \mathrm{C}$; no growth was observed at 4 or $40{ }^{\circ} \mathrm{C}$. All further incubations were at $22{ }^{\circ} \mathrm{C}$ unless otherwise noted. Growth occurred in 
the absence of vitamins and yeast extract. Cells growing on glucose with a $\mathrm{N}_{2}$ headspace were used for $\mathrm{pH}$ and temperature experiments. For $\mathrm{pH}$ experiments, the following Good's buffers (Sigma-Aldrich) were used $\left(30 \mathrm{~g} \mathrm{l}^{-1}\right)$ : HOMOPIPES (pH 5.0 and 5.5), MES (pH 6.0 and 6.5), TES (pH 7.0 and 7.5), TAPS (pH 8.0 and 8.5), CAPSO (pH 9.0) and CAPS ( $\mathrm{pH} 10.0$ and 10.5). The isolate grew at $\mathrm{pH} 5.5-$ 8.5 , with optimum growth at $\mathrm{pH} 7.5$; no growth was observed at $\mathrm{pH} 5.0$ or 9.0. The isolate was rod-shaped (2.4$3.6 \mu \mathrm{m}$ long and $0.9 \mu \mathrm{m}$ wide) and non-motile, similar to $T$. auensis (Fischer-Romero et al., 1996). The Gram reaction was examined using the Hucker method (Beveridge et al., 2007) and a $\mathrm{KOH}$ lysis test (Tindall et al., 2007). An overnight culture of strain OCF $7^{\mathrm{T}}$ stained Gram-negative and was positive for lysis in the $\mathrm{KOH}$ test. Nutritional requirements and substrate use were examined as described previously (Liou et al., 2005). Positives were scored by an increase in optical density and serial passage compared with negative controls. The isolate was characterized biochemically by using a combination of conventional tests as described previously (Tindall et al., 2007). Cells grown aerobically on tryptic soy agar (TSA; Difco) at $22{ }^{\circ} \mathrm{C}$ were screened using the Biolog GN2 MicroPlate. Cells grown anaerobically on tryptic soy broth (TSB) at $22{ }^{\circ} \mathrm{C}$ were screened using the API Rapid ID 32 A and API ZYM test systems (bioMérieux) according to the manufacturer's instructions. Acids and alcohols were quantified as described previously (Allen et al., 2008). Fatty acid methyl ester (FAME) analysis was performed on overnight cultures grown on TSA at $22{ }^{\circ} \mathrm{C}$ by the Identification Service of the Deutsche Sammlung von Mikroorganismen und Zellkulturen (DSMZ), Braunschweig, Germany, as described previously (Miller, 1982; Sasser, 1990). Polar lipid and respiratory quinone analysis was carried out by the Identification Service of the DSMZ and Dr Brian J. Tindall (DSMZ).

The ability to transform substituted aromatic compounds to toluene or phenol was examined under anaerobic conditions using the basal medium described above and was tested in both the presence and absence of glucose $(0.5 \%)$. Aromatic substrates were amended from sterile, anoxic stock bottles to an initial concentration of $2 \mathrm{mM}$ and included phenylacetate, phenylalanine, phenoxyacetate, phenylsuccinate, phenylbutyrate and tyrosine (Sigma). A series of tubes in which various amounts of phenylacetate $(50,100,200,400$ and $600 \mu \mathrm{M})$ were added in the presence of glucose $(0.5 \%)$ was also examined to look at concentration effects. Toluene was determined by headspace analysis with a Hewlett Packard 5890 series II GC equipped with a flame-ionization detector and a DB-1 capillary column (J\&W Scientific), operated isothermally at $150{ }^{\circ} \mathrm{C}$. Phenol was measured by HPLC using a Prevail $\mathrm{C}_{18}$ reversed-phase column (Alltech) with a mobile phase of $25 \mathrm{mM} \mathrm{KH}_{2} \mathrm{PO}_{4} / \mathrm{CH}_{3} \mathrm{CN}(50: 50)$ at a flow rate of $0.9 \mathrm{ml} \mathrm{min}^{-1}$.

When grown anaerobically, strain OCF $7^{\mathrm{T}}$ and T. auensis DSM $9187^{\mathrm{T}}$ can be differentiated by their abilities to use arabinose, fumarate, lactose and pyruvate and to hydrolyse urea (Table 1; see species description for full list of
Table 1. Characteristics useful for distinguishing between strain OCF $7^{\top}$ and $T$. auensis DSM $9187^{\top}$ when grown anaerobically

Data from this study and Fischer-Romero et al. (1996).

\begin{tabular}{|lcc|}
\hline Characteristic & OCF $\mathbf{7}^{\mathbf{T}}$ & T. auensis DSM $\mathbf{~ 9 1 8 7 ~}^{\mathbf{T}}$ \\
\hline pH range (optimum) & $5.5-8.5(7.5)$ & $6.0-7.5(7.2)$ \\
Utilization of: & - & \\
$\quad$ Arabinose & + & + \\
Fumarate & + & - \\
Lactose & + & - \\
Pyruvate & + & - \\
Hydrolysis of urea & F, A, E, L & F, A, E \\
Major products from & & \\
glucose & 52 & 49 \\
DNA G+C content & & \\
(mol\%) & & \\
\hline
\end{tabular}

${ }^{\star} \mathrm{A}$, Acetate; E, ethanol; F, formate; L, lactate.

substrates). Major end products from glucose for strain OCF $7^{\mathrm{T}}$ were formate, acetate, ethanol and lactate (Table 1). In addition, trace amounts of pyruvate were also produced. $T$. auensis DSM $9187^{\mathrm{T}}$ produces acetate, ethanol and formate as end products of peptone-yeast extract-glucose metabolism. However, the greatest difference between $T$. auensis DSM $9187^{\mathrm{T}}$ and strain OCF $7^{\mathrm{T}}$ was the ability to form toluene from substituted aromatic compounds in the presence of other substrates (on which the genus name was based). T. auensis DSM $9187^{\mathrm{T}}$ can produce toluene from phenylacetate, phenylalanine, phenyllactate and phenylpyruvate (and phenol from tyrosine) in the presence of a usable carbon source (Fischer-Romero et al., 1996). Strain OCF $7^{\mathrm{T}}$ did not anaerobically transform phenylacetate, phenylalanine or similarly related compounds, phenylbutyrate, phenylsuccinate or phenoxyacetate, in the presence of glucose even after 70 days of incubation (data not shown). Furthermore, strain OCF $7^{\mathrm{T}}$ did not transform tyrosine or phenoxyacetate to phenol. Toluene and phenol were not produced in substrateunamended controls either. Although overnight growth of strain OCF $7^{\mathrm{T}}$ on glucose was unaffected by the starting concentration of the aromatic compounds, a series of tubes was prepared to evaluate the effect of concentration. Again, in the presence of glucose, toluene was not detected after 70 days of incubation when the starting concentration of phenylacetate was 50-600 $\mu \mathrm{M}$. Other differences between $T$. auensis DSM $9187^{\mathrm{T}}$ and strain OCF $7^{\mathrm{T}}$ were observed when aerobically grown cells were tested with the $24 \mathrm{~h}$ Biolog GN2 MicroPlate. Of the 95 substrates tested for catabolism in the Biolog plate, only four substrates were positive for both micro-organisms: glucose, fructose, galactose and arabinose. The other substrates exhibited opposite reactions or were not utilized by either micro-organism (see Supplementary Table S1, available in IJSEM Online).

Whole-cell fatty acid analysis of strain OCF $7^{\mathrm{T}}$ revealed $\mathrm{C}_{12: 0} \quad(4.2 \%), \mathrm{C}_{14: 0} \quad(4.9 \%), \mathrm{C}_{16: 0} \quad(22.3 \%), \mathrm{C}_{18: 1} \omega 7 c$ 
(19.0\%), a summed feature of $\mathrm{C}_{16: 1} \omega 7 c$ and/or iso- $\mathrm{C}_{15: 0} 2$ $\mathrm{OH}(43.3 \%)$ and a summed feature of $\mathrm{C}_{14: 0} 3-\mathrm{OH}$ and/or iso- $\mathrm{C}_{16: 1} \mathrm{I}(4.5 \%)$ as the primary fatty acids. Strain OCF $7^{\mathrm{T}}$ was also grown aerobically on TSA and on the basal toluene production medium of Fischer-Romero et al. (1996). Cellular fatty acid composition of the isolate was stable when grown on different media and under different conditions (Supplementary Table S2). This FAME analysis agrees well with that of $T$. auensis, the major fatty acids of which were reported to be $\mathrm{C}_{12: 0}, \mathrm{C}_{14: 0}, \mathrm{C}_{14: 0} 3-\mathrm{OH}$, $\mathrm{C}_{16: 1} \omega 7 c, \mathrm{C}_{16: 0}$ and $\mathrm{C}_{18: 1} \omega 7 c$ (Fischer-Romero et al., 1996). The summed feature $\mathrm{C}_{16: 1} \omega 7 c$ and/or iso- $\mathrm{C}_{15: 0} 2-\mathrm{OH}$ is probably the single fatty acid $\mathrm{C}_{16: 1} \omega 7 c$, reported as the dominant fatty acid in the phylogenetically close neighbours of strain OCF $7^{\mathrm{T}}$, Oceanimonas doudoroffii (42\%) (Brown et al., 2001) and Oceanisphaera litoralis (41\%) (Romanenko et al., 2003). Although Oceanisphaera donghaensis (46.2\%) (Park et al., 2006) and Aeromonas sharmana (29.3\%) (Saha \& Chakrabarti, 2006) also present the summed feature $\mathrm{C}_{16: 1} \omega 7 c$ and/or iso- $\mathrm{C}_{15: 0} 2-\mathrm{OH}$ as their dominant fatty acid, it should be noted that 2-hydroxy fatty acids have not been detected in members of any closely related genera, namely Tolumonas, Aeromonas, Vibrio, Haemophilus, Actinobacillus, Pasteurella, Succinivibrio, Succinimonas, Anaerospirillum or Ruminobacter (Fischer-Romero \& Tindall, 2005).

As with T. auensis, the major polar lipids for strain OCF $7^{\mathrm{T}}$ were determined to be phosphatidylglycerol and phosphatidylethanolamine. The presence of phospholipid and aminophospholipid was also detected in strain OCF $7^{\mathrm{T}}$. However, the respiratory quinones of strain OCF $7^{\mathrm{T}}$ differed from those of $T$. auensis. The respiratory quinone of strain OCF $7^{\mathrm{T}}$ grown on TSB $\left(22{ }^{\circ} \mathrm{C}\right)$ under both aerobic and anaerobic conditions was menaquinone MK-8 (100\%), whereas respiratory quinones of T. auensis were Q-8 and MK-8 (Fischer-Romero et al., 1996). Like T. auensis, strain OCF $7^{\mathrm{T}}$ was catalase-positive and oxidase-negative.

The ability to reduce nitrate (but not denitrify) is a common characteristic among members of the family Aeromonadaceae (Brown et al., 2001; Martin-Carnahan \& Joseph, 2005a; Martin-Carnahan \& Joseph, 2005b; Park et al., 2006; Romanenko et al., 2003). However, strain OCF $7^{\mathrm{T}}$ did not reduce nitrate (the result for nitrate reduction by $T$. auensis is not known).

DNA G $+\mathrm{C}$ content was determined by HPLC (Mesbah et al., 1989) using a Prevail $C_{18}$ reversed-phase column (Alltech) at room temperature with a mobile phase of $25 \mathrm{mM}$ $\mathrm{KH}_{2} \mathrm{PO}_{4}: \mathrm{CH}_{3} \mathrm{CN}$ (96:4), pH 2.5. The genomic DNA $\mathrm{G}+\mathrm{C}$ content was $52.1 \pm 0.1 \mathrm{~mol} \%$. The $16 \mathrm{~S}$ rRNA gene of strain OCF $7^{\mathrm{T}}$ was amplified by PCR using the universal primers 27F (5'-AGAGTTTGATCCTGGCTCAG) and 1492R (5'-GGCTACCTTGTTACGACTT) (numbers of primers refer to positions relative to the Escherichia coli $16 \mathrm{~S}$ rRNA gene) (Madrid et al., 2001). Amplified products were treated with ExoSAP-IT (USB) and sequenced directly with primers directed towards conserved positions of the $16 \mathrm{~S}$ rRNA gene. Sequencing reactions were performed using the
BigDye Terminator cycle sequencing kit, version 3.1 (Applied Biosystems), as described by the manufacturer and were analysed using an Applied Biosystems 3730 DNA analyser. The closest known relatives of the isolate were determined by performing database searches using the program FASTA (Lipman \& Pearson, 1985). These sequences and those of other related strains were retrieved from GenBank and aligned with the newly determined sequence using the program SEQtools (Rasmussen, 2002). The resulting multiple sequence alignment was corrected manually using the program GeneDoc (Nicholas et al., 1997) and a phylogenetic tree was constructed according to the neighbour-joining method (Saitou \& Nei, 1987) with the programs SEQtools and TreeView (Page, 1996). Phylogenetic analysis was performed on 1320 shared nucleotides using the neighbourjoining and maximum-parsimony algorithms; the stability of the groupings was estimated by bootstrap analysis (1000 replications) using the same programs. Sequence searches of GenBank and Ribosomal Database Project libraries revealed that the unknown organism was a member of the family Aeromonadaceae in the Gammaproteobacteria. It is evident from treeing analysis that strain OCF $7^{\mathrm{T}}$ is specifically related to the type strain of $T$. auensis. A pairwise comparison revealed a $2.8 \%$ sequence divergence based on the almost fulllength 16S rRNA gene sequences (1516 nt). A phylogenetic tree, constructed by the neighbour-joining method, depicting the phylogenetic position of OCF $7^{\mathrm{T}}$ is shown in Fig. 1. All major branching nodes were confirmed by maximumparsimony (not shown). Other phylogenetic neighbours of strain OCF $7^{\mathrm{T}}$ all had $<95 \% 16 \mathrm{~S}$ rRNA gene sequence similarity, specifically the type strains of A. sharmana (94.3\%), Aeromonas hydrophila (93.0\%), Oceanimonas doudoroffii (91.3\%) and Oceanisphaera litoralis (90.6\%).

While there is no precise correlation between the level of $16 \mathrm{~S}$ rRNA gene sequence divergence and species delineation, studies by Stackebrandt \& Ebers (2006) demonstrated that sequence similarity values between novel species could be as high as almost $99 \%$ without loss of resolution and recommended mandatory DNA-DNA hybridization only for values above $98.7-99.0 \%$ sequence similarity. Although tree topology and sequence divergence values $(2.8 \%)$ showed that the unidentified rod-shaped organism warrants classification within a novel species, its genus assignment is somewhat problematic. A significant characteristic of $T$. auensis is its ability to transform phenylacetate, phenylalanine and substituted aromatic acids into toluene, but strain OCF $7^{\mathrm{T}}$ did not exhibit this activity. However, FAME analysis, biochemical and polar lipid data are all compatible with the genus Tolumonas. From a practical standpoint, the proliferation of taxa based on just a few morphological, biochemical or even chemotaxonomic criteria should be avoided and robust taxonomic units retained where possible. While debate has occurred on the validity of describing novel genera and species based on a single strain, it is important to name novel taxa based on thorough polyphasic studies to allow other members of the scientific community to identify these bacteria as other 


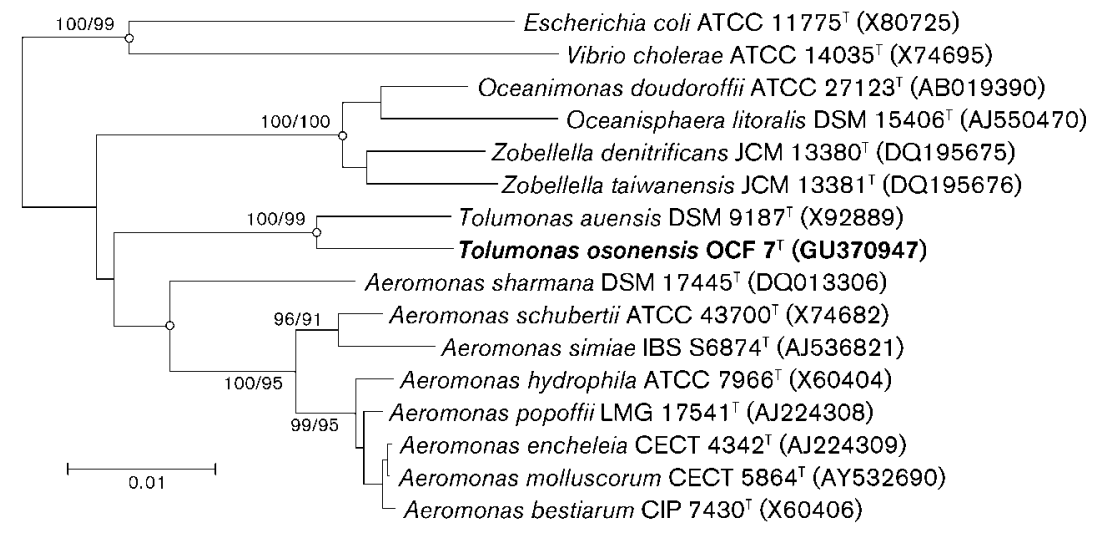

Fig. 1. Unrooted tree showing the phylogenetic relationships of strain OCF $7^{\top}$ (Tolumonas osonensis sp. nov.) and closely related microorganisms within the Gammaproteobacteria. Circles indicate generic branches that were present in both phylogenetic consensus trees generated by the neighbour-joining and maximum-parsimony algorithms. Numbers at nodes indicate bootstrap values, expressed as percentages of 1000 replications, calculated by neighbour-joining/maximum-parsimony probabilities; only values above $90 \%$ are shown. Bar, 1 substitution per 100 nucleotide positions.

strains of them are recovered. Thus, based on the presented phylogenetic and phenotypic evidence, it is proposed that the unidentified isolate recovered from anoxic freshwater creek sediment be assigned to the genus Tolumonas, within the novel species Tolumonas osonensis sp. nov. In addition to its unique $16 \mathrm{~S}$ rRNA gene sequence, strain OCF $7^{\mathrm{T}}$ can be distinguished from T. auensis by characteristics shown in Table 1 and Supplementary Table S1.

\section{Emended description of the genus Tolumonas Fischer-Romero et al. 1996}

The phenotypic description of Tolumonas is essentially the same as that in Bergey's Manual of Systematic Bacteriology (Fischer-Romero \& Tindall, 2005) based on that of FischerRomero et al. (1996) with the following changes. May or may not produce toluene from phenylacetate or phenylalanine in the presence of another carbon source. May or may not produce phenol from tyrosine in the presence of another carbon source. May or may not utilize arabinose, fumarate, lactose or pyruvate. May or may not have the ability to hydrolyse urea. End products from glucose are acetate, ethanol, formate and/or lactate. Grows between $\mathrm{pH} 5.5$ and 8.5. DNA G $+\mathrm{C}$ content is $49-52 \mathrm{~mol} \%$.

\section{Description of Tolumonas osonensis sp. nov.}

Tolumonas osonensis (o.so.nen'sis. N.L. fem. adj. osonensis pertaining to Oso Creek, Corpus Christi, Texas, USA, where the type strain was isolated).

Cells are non-motile, Gram-negative rods (2.4-3.6 $\mu \mathrm{m}$ long and $0.9 \mu \mathrm{m}$ wide) and are found singly, in pairs or occasionally in short chains. Facultative anaerobe. Grows at $15-37{ }^{\circ} \mathrm{C}$ (optimum, $22{ }^{\circ} \mathrm{C}$ ) and $\mathrm{pH}$ 5.5-8.5 (optimum, $\mathrm{pH}$ 7.5). Vitamins or yeast extract are not required for growth. Glucose, fructose, cellobiose, melezitose, maltose, lactose, galactose, sucrose, ribose, raffinose, melibiose, trehalose, mannose, turanose, glycogen, mannitol, sorbitol, amygdalin, pyruvate, fumarate, salicin, aesculin, inulin, $\mathrm{N}$ acetyl-D-glucosamine and yeast extract are used as growth substrates. Arabinose, xylose, glycerol, starch, inositol, adonitol, malate, glycolate, choline, betaine, trimethylamine, formate, acetate, propionate, butyrate, lactate, succinate, methanol, ethanol, n-propanol, n-butanol, peptone, tryptone, Casamino acids, $\mathrm{H}_{2} / \mathrm{CO}_{2}$ and $\mathrm{CO} / \mathrm{CO}_{2}$ are not utilized. Urea is hydrolysed, but cellulose, gelatin, chitin and starch are not. Nitrate and sulfate are not reduced. End products from glucose are formate, acetate, ethanol and lactate. Toluene is not formed from phenylacetate, phenylalanine, phenylsuccinate, phenylbutyrate or phenoxyacetate in the presence of glucose. Phenol is not formed from tyrosine or phenoxyacetate. Under oxic conditions, catabolizes the following organic substrates when analysed with the $24 \mathrm{~h}$ Biolog GN2 MicroPlate: $N$-acetyl-D-glucosamine, L-arabinose, cellobiose, D-fructose, D-galactose, gentiobiose, $\alpha$-Dglucose, lactose, lactulose, maltose, D-mannitol, D-mannose, melibiose, methyl $\beta$-D-glucoside, D-psicose, raffinose, Dsorbitol, sucrose, trehalose and turanose. Using the API Rapid ID 32A kit, positive reactions are observed for $\alpha$ galactosidase, $\beta$-galactosidase, $\alpha$-glucosidase, $\beta$-glucosidase, arginine arylamidase, leucine arylamidase (weak), alanine arylamidase, glycine arylamidase and serine arylamidase. Furthermore, mannose and raffinose are fermented. Activity is not detected for urease, arginine dihydrolase, $\beta$-galactosidase-6-phosphate, $\alpha$-arabinosidase, $\beta$-glucuronidase, $N$ acetyl- $\beta$-glucosaminidase, glutamic acid decarboxylase, $\alpha$ fucosidase, alkaline phosphatase, proline arylamidase, leucyl glycine arylamidase, phenylalanine arylamidase, pyroglutamic acid arylamidase, tyrosine arylamidase, histidine arylamidase and glutamyl glutamic acid arylamidase. In addition, indole is not produced and nitrate is not reduced. Using the API ZYM kit, positive enzyme activities are high for $\beta$-galactosidase and $\beta$-glucosidase, moderate for esterase (C4), leucine arylamidase, $\alpha$-galactosidase and $\alpha$-glucosidase and weak for alkaline phosphatase, esterase lipase (C8), acid phosphatase and naphthol-AS-BI-phosphohydrolase. Lipase (C14), leucine arylamidase, valine arylamidase, cystine arylamidase, trypsin, $\alpha$-chymotrypsin, $\alpha$-galactosidase, $\beta$ glucuronidase, $N$-acetyl- $\beta$-glucosaminidase, $\alpha$-mannosidase and $\alpha$-fucosidase activities are not detected. The major longchain fatty acids are $\mathrm{C}_{16: 0}, \mathrm{C}_{18: 1} \omega 7 c$ and $\mathrm{C}_{16: 1} \omega 7 c$ (and/or iso- $\mathrm{C}_{15: 0}$ 2-OH). Catalase-positive and oxidase-negative when grown aerobically. The respiratory quinone under both aerobic and anaerobic conditions is menaquinone 
MK-8. Major polar lipids are phosphatidylethanolamine and phosphatidylglycerol.

The type strain is OCF $7^{\mathrm{T}}\left(=\right.$ DSM $22975^{\mathrm{T}}=$ ATCC BAA$\left.1908^{\mathrm{T}}\right)$, isolated from anoxic sediment of a freshwater creek. The DNA G +C content of the type strain is $52 \mathrm{~mol} \%$.

\section{Acknowledgements}

The authors wish to acknowledge Hans G. Trüper for assistance with Latin nomenclature. This work was supported by a grant from the Oklahoma Bioenergy Center.

\section{References}

Allen, T. D., Kraus, P. F., Lawson, P. A., Drake, G. R., Balkwill, D. L. \& Tanner, R. S. (2008). Desulfovibrio carbinoliphilus sp. nov., a benzyl alcohol-oxidizing, sulfate-reducing bacterium isolated from a gas condensate-contaminated aquifer. Int J Syst Evol Microbiol 58, 13131317.

Berthelot, A. (1917). Production of phenol by bacteria. C R Acad Sci 164, 196-199.

Beveridge, T. J., Lawrence, J. R. \& Murray, R. G. E. (2007). Sampling and staining for light microscopy. In Methods for General and Molecular Microbiology, pp. 19-33. Edited by C. A. Reddy, T. J. Beveridge, J. A. Breznak, G. A. Marzluf, T. M. Schmidt \& L. R. Snyder. Washington, DC: American Society for Microbiology.

Brown, G. R., Sutcliffe, I. C. \& Cummings, S. P. (2001). Reclassification of [Pseudomonas] doudoroffii (Baumann et al. 1983) into the genus Oceanomonas gen. nov. as Oceanomonas doudoroffii comb. nov., and description of a phenol-degrading bacterium from estuarine water as Oceanomonas baumannii sp. nov. Int J Syst Evol Microbiol 51, 67-72.

Chen, T. C. \& Levin, R. E. (1975). Isolation of Aeromonas sp. ATCC 29063, a phenol-producing organism, from fresh haddock. Appl Microbiol 30, 120-122.

Elsden, S. R., Hilton, M. G. \& Waller, J. M. (1976). The end products of the metabolism of aromatic amino acids by clostridia. Arch Microbiol 107, 283-288.

Fischer-Romero, C. \& Tindall, B. J. (2005). Genus incertae sedis III. Tolumonas Fischer-Romero, Tindall and Jüttner 1996, $187^{\mathrm{VP}}$. In Bergey's Manual of Systematic Bacteriology, 2nd edn, vol. 2B, pp. 579581. Edited by G. M. Garrity, D. J. Brenner, N. R. Krieg \& J. T. Staley. New York: Springer.

Fischer-Romero, C., Tindall, B. J. \& Jüttner, F. (1996). Tolumonas auensis gen. nov., sp. nov., a toluene-producing bacterium from anoxic sediments of a freshwater lake. Int J Syst Bacteriol 46, 183-188.

Hungate, R. E. (1969). A roll tube method for cultivation of strict anaerobes. Methods Microbiol 3B, 117-132.

Lin, Y.-T. \& Shieh, W. Y. (2006). Zobellella denitrificans gen. nov., sp. nov. and Zobellella taiwanensis sp. nov., denitrifying bacteria capable of fermentative metabolism. Int J Syst Evol Microbiol 56, 1209-1215.

Liou, J. S., Balkwill, D. L., Drake, G. R. \& Tanner, R. S. (2005). Clostridium carboxidivorans sp. nov., a solvent-producing clostridium isolated from an agricultural settling lagoon, and reclassification of the acetogen Clostridium scatologenes strain SL1 as Clostridium drakei sp. nov. Int J Syst Evol Microbiol 55, 2085-2091.
Lipman, D. J. \& Pearson, W. R. (1985). Rapid and sensitive protein similarity searches. Science 227, 1435-1441.

Madrid, V. M., Taylor, G. T., Scranton, M. I. \& Chistoserdov, A. Y. (2001). Phylogenetic diversity of bacterial and archaeal communities in the anoxic zone of the Cariaco Basin. Appl Environ Microbiol 67, 1663-1674.

Martin-Carnahan, A. \& Joseph, S. W. (2005a). Family I. Aeromonadaceae Colwell, MacDonell and De Ley 1986, $474^{\mathrm{VP}}$. In Bergey's Manual of Systematic Bacteriology, 2nd edn, vol. 2B, p. 556. Edited by G. M. Garrity, D. J. Brenner, N. R. Krieg \& J. T. Staley. New York: Springer.

Martin-Carnahan, A. \& Joseph, S. W. (2005b). Genus I. Aeromonas Stanier 1943, 213 ${ }^{\mathrm{AL}}$. In Bergey's Manual of Systematic Bacteriology, 2nd edn, vol. 2B, pp. 557-578. Edited by G. M. Garrity, D. J. Brenner, N. R. Krieg \& J. T. Staley. New York: Springer.

Mesbah, M., Premachandran, U. \& Whitman, W. B. (1989). Precise measurement of the $\mathrm{G}+\mathrm{C}$ content of deoxyribonucleic acid by highperformance liquid chromatography. Int J Syst Bacteriol 39, 159-167.

Miller, L. T. (1982). Single derivatization method for routine analysis of bacterial whole-cell fatty acid methyl esters, including hydroxy acids. J Clin Microbiol 16, 584-586.

Nicholas, K. B., Nicholas, H. B., Jr \& Deerfield, D. W., II (1997). GeneDoc: analysis and visualization of genetic variation. EMBnet News 4 (2), 1-4. http://www.nrbsc.org/gfx/genedoc/ebinet.htm

Page, R. D. M. (1996). TreeView: an application to display phylogenetic trees on personal computers. Comput Appl Biosci 12, 357-358.

Park, S.-J., Kang, C.-H., Nam, Y.-D., Bae, J.-W., Park, Y.-H., Quan, Z.-X., Moon, D.-S., Kim, H.-J., Roh, D.-H. \& Rhee, S.-K. (2006). Oceanisphaera donghaensis sp. nov., a halophilic bacterium from the East Sea, Korea. Int J Syst Evol Microbiol 56, 895-898.

Rasmussen, S. W. (2002). SEQtools, a software package for analysis of nucleotide and protein sequences. http:/www.seqtools.dk/

Romanenko, L. A., Schumann, P., Zhukova, N. V., Rohde, M., Mikhailov, V. V. \& Stackebrandt, E. (2003). Oceanisphaera litoralis gen. nov., sp. nov., a novel halophilic bacterium from marine bottom sediments. Int J Syst Evol Microbiol 53, 1885-1888.

Saha, P. \& Chakrabarti, T. (2006). Aeromonas sharmana sp. nov., isolated from a warm spring. Int J Syst Evol Microbiol 56, 1905-1909.

Saitou, N. \& Nei, M. (1987). The neighbor-joining method: a new method for reconstructing phylogenetic trees. Mol Biol Evol 4, 406425.

Sasser, M. (1990). Identification of bacteria by gas chromatography of cellular fatty acids, MIDI Technical Note 101. Newark, DE: MIDI, Inc.

Stackebrandt, E. \& Ebers, J. (2006). Taxonomic parameters revisited: tarnished gold standards. Microbiol Today 33, 152-155.

Tanner, R. S. (2007). Cultivation of bacteria and fungi. In Manual of Environmental Microbiology, 3rd edn, pp. 69-78. Edited by C. J. Hurst, R. L. Crawford, A. L. Mills, J. L. Garland, L. D. Stetzenbach \& D. A. Lipson. Washington, DC: American Society for Microbiology.

Tindall, B. J., Sikorski, J., Smibert, R. A. \& Krieg, N. R. (2007). Phenotypic characterization and the principles of comparative systematics. In Methods for General and Molecular Microbiology, pp. 330-393. Edited by C. A. Reddy, T. J. Beveridge, J. A. Breznak, G. A. Marzluf, T. M. Schmidt \& L. R. Snyder. Washington, DC: American Society for Microbiology. 